\title{
Homebound Documentaries: A Reflection upon the Significance of Self- reflexive Cinema in the Digital Age
}

\author{
Nikbanoo Ardalan \\ The University of Sydney, Australia
}

\begin{abstract}
Homebound documentaries consist of self-reflexive autobiographical works of cinema that do not pertain to traditional film conventions and thus do not fit the traditional definition of a film. These productions are primarily home based and address stories concerned with the challenges of their directors as they take part in daily life activities which is quite similar to the content matter of video blogs shared online. The self-reflexive component of these non-films has a significant similarity to the format of digital audiovisual content that is shared on social media platforms as they invite the audience to engage in critical thought and interact with their narrative. The following paper will discuss these ideas based on the analysis of Jafar Panahi's This Is Not a Film (2011) and Chantal Akerman's No Home Movie (2015).
\end{abstract}

Keywords: Self-reflexivity, Digital cinema, Film conventions, Autobiographical documentary, Vlog

\section{Introduction}

Cinema, like other art forms, is constantly evolving and filmmaking is constantly adapting to the historical, social and cultural norms that each time period is characterized by as films are reflections of society's interests. According to Bordwell $(2007,86)$, narrative and storytelling are essential components of human life and history. The communication of experiences has always been a driving factor in the purpose of building a narrative or telling a story. With the development of various mediums and access to different modes of exposition such as verbal, textual and visual, the possibility of communicating ideas that extend beyond reality has become viable; which, in turn, has established certain conventions and structures that have become expected when reading a novel or watching a film. While many films and directors adhere to the expectations of cinematic conventions in terms of genre, filmic narrative and directing process, there have been a number of instances in cinema history where these conventions have been challenged to question the definition of a film and provoke the audience to engage in critical thinking rather than passive viewership.

In the following paper I am going to consider the significance of self-reflexive cinema in two homebound documentaries ${ }^{1}$, namely This Is Not a Film (2011) directed by Jafar Panahi and No Home Movie (2015) directed by Chantal Akerman, that challenge cinematic conventions and traditions and reflect on the socio-cultural characteristics of reality in the digital age not only in form but also in content. The peculiarity of these two cases provides a good example of the following statement made by Ruby about the specific nature of these works as

\section{The development of non-fiction films dealing with the filmmakers' own family and their immediate world seems to represent a non-fiction genre which fits neither the traditional definition of the documentary nor the personal art film. In fact, these films violate canons of both genres. (Ruby 1977, 8)}

While No Home Movie (2015) can be better characterized as part autobiographical and part biographical since Akerman's vision was to capture Natalia's story alongside her and her mother's bond, This Is Not a Film (2011) only focuses on the director, Jafar Panahi, although the entirety of the events take place in the span of a day and not much of the past is reminisced, occurrences that are taking place in the present time throughout the day are documented. These non-films are structured around daily life in a home atmosphere while addressing challenging realities that the directors are facing which has resulted in the production of these films to also challenge the process of filmmaking as the audience is no longer bound by a distinction of what is happening on screen and off screen. This mode of filmmaking has significant resemblance to the genres of audiovisual content that can be found on social networking platforms such as video blogs where the audience is invited to join content creators in their daily ventures and interact with the shared content as it progresses. Künüçen $(2014,239)$ refers to these shifts from conventional cinema towards to the innovations brought by the digital filmmaking as the 'new film language' that can be observed in more recent cinematic productions. Starting by the way in which these documentaries challenge and differ from traditional filmmaking, I am going to analyze and discuss the different ways in which the self-reflexive characteristics of these non-films impact the relationship with the audiences viewing experience as well as the relationship with the cinematic medium in the digital context.

\section{Cinema of attractions and filmic narrative}

Initially, when the very first film cameras were pioneered, the art of filmmaking was referred to as the cinema of attractions because the movies at the time focused on the visual exposition of images rather than narrative development (Gunning 2006, 382). The potential of the cinematic medium has since allowed filmmakers to incorporate the component of artifice and illusion within the art form in the stages of production and post-production to realize their creative vision. 
Eventually when the cinema of attractions started incorporating narrative structure and adapting into a storytelling medium, this potential became part of the cinematic experience, especially in fictional genres, which aimed to engage and transport the audience from the real world into the magic of the cinematic screen (Gunning 2006, 382). The development of narrative structure and conventions is one of the main differences that can be attributed to cinema before 1906 as this created the distinction between the composition of narrative and non-narrative films (Gunning 2006, 382).

The early considerations regarding the study of narrative parameters were mainly focused on the literary domain of storytelling (Bordwell 2007, 89). Consequently, after the development of technology that enabled the establishment of mediums that transcended verbal and written communication, the paradigm of narrative was also considered in other types of communication. The concept of narratology came to be in the twentieth century as storytelling structure and conventions had become an important point of enquiry in various creative fields including painting, literature, theater and cinema (Bordwell 2007, 85). However, the definitions of narrative and discourse have been differentiated in regards to different art forms since the Classical period when Aristotle indicated that different types of poetic writing reflected on external actions while others included the author's inner thoughts (Poulaki 2012, 1). The presence of the figure of "the Narrator" in a film such as Fight Club (1999) provides a good example of this differentiation as two characters (the Narrator and Tyler Durden) are presented to the audience which seemingly take the role of embodying each concept separately; although, in reality the projection of discourse and narrative are overlapping through the presence of a single character that suffers from split personality disorder.

\section{Media convergence in the $21^{\text {st }}$ century}

One of the aspects that Bordwell (2007, 94) examines as a part of narration is the importance of culture and convergence, as comprehension is an essential part of narrative functionality. Films have developed into a variety of categorizations over the years; movies with certain themes and specific target audiences are demarcated within a rating system, movies with specific topics, conventions and intentions are assigned to different genres but also differentiated based on their portrayal of reality into fiction and non-fiction categories. Cinema as an art form has also undergone a development in categorization as filmmaking practices and watching movies are no longer restricted to the affordances of the film camera and cinema theaters.

One of the many socio-cultural changes that has occurred with the development of new media in regards to daily media consumption and audience experience within the cinematic context is the usage of multiple devices or screens at once while engaging with different media formats. Friedberg (2006, 6-7), attributes this effect of the affordances of digital media devices through the process of convergence which now allows audiences to access the cinematic screen outside the movie theater.

In the twenty-first century, the use of smartphones has become a consistent part of daily life and has become embedded into various aspects of current society and culture in the digital age. The art of filmmaking was previously only restricted to those who had access to professional audiovisual equipment, film studios and individuals with proficient skill level and industry knowledge (Künüçen 2014, 239-240). The affordances of the smartphone, specifically the access to a portable camera device, in addition to the affordances of online media sharing platforms such as YouTube and Vimeo have provided an opportunity for the general public to participate and redefine the traditional conventions of filmmaking. The movie Jongo Love (2015), was shot on a mobile phone and distributed to the public via YouTube. The self-reflexivity in Jongo Love (2015) can be considered in the way that the device that was used in the process stage is also a crucial part of the product stage as well as how it serves the purpose to communicate the affordances of filmmaking offered by a digital device can be accessed by virtually anyone (Kings 2017, 74-76).

Media convergence has encouraged the occurrence of transmedia and screen-based multitasking. Friedberg (2006, 233-234) describes this as a modern cultural phenomenon where society engages in the use of multiple devices simultaneously. In This Is Not a Film (2011) there are many instances of this happening as Panahi is often seen engaging with multiple screens and devices at once which strongly reflects on how culture and convergence play a significant role in the realistic depiction of everyday life in the twenty-first century. Films can not only be viewed on a smartphone but also made using a smartphone and have smartphones featured in them. The use of digital screens and devices in any part of filmmaking is no longer a deviation from the art but an inevitable part of it. In No Home Movie (2015), a noteworthy scene features Chantal recording her mother while being on a Skype call with her where she explains that the physical distance between her and her mother do not affect their relationship as they are always keeping in touch. Once again the digital screen is shown within the cinematic context as a realistic part of mundanity.

\section{The effects of the fourth wall on passive spectatorship}

The very concept of denominating the space which puts a divide between the actors and the audience as the 'fourth wall' shows how the audience is positioned into an alienating stance (Davis 2015, 87). While this convention was initially established in theater and performance arts, it was also later adopted in cinema 
for the purpose of comedic effect such in Charlie Chaplin's films where he would purposely acknowledge the presence of the camera to create certain gags (Davis 2015, 87). In the context of fictional cinema, the establishment of the fourth wall helps to maintain the fascination of the fantasy that is happening on the screen albeit resulting in a passive viewing towards the events on the screen.

Brecht's idea of breaking the fourth wall in the theatric context was intended to involve the audience as witnesses engaged in critical thought when faced with the socio-political challenges that the characters of his plays endured rather than spectators reacting to a story that is closed off in another world that they are not a part of (Davis 2015, 88). Considering this, in the case of non-fiction cinema the breaking of the fourth wall could actually become an asset as the reality of human experiences can be universally experienced and understood. In one scene, Chantal asks her mother to "Tell us a story", a simple request that attracts the audience's attention towards what Natalia has to say as she was slowly succumbing to illness which was quite impactful due to the fact that the audience's emotional investment is involved a real story involving real people and not an adaptation or script portraying a certain reality (No Home Movie 2015). There is no behind the scene segment that the audience can view to obtain a sense of comfort or relief due to the emotional reaction caused by the events that were showcased in the film as Chantal is sharing moments of legitimate distress happening in real time with the audience which can also be considered as raw footage.

Brecht's critique of the fourth wall raises an important concern towards the trivialization of stories that take place in the reality of the lived world and the reactions produced in response to them (Davis 2015, 89). As Natalia was a Holocaust survivor, the impact of her story alone is encaptivating enough to establish an emotional connection even without the aesthetic, formal or structural conventions of film narrative. Hence, the audience's connection with Natalia's story would not become as powerful if the audience were to view No Home Movie (2015) from a position of alienation. Similarly, Panahi's description of the script that he has written for an upcoming project that cannot be realized due to his circumstances, which later results in frustration as he expresses his exasperation about the fact that telling a film is not the same as making a film which reflects on the effects of the socio-political challenges he was facing (This Is Not a Film 2011).

\section{Self-reflexivity and the autobiographical documentary}

The conventions of non-fictional genres, such as the documentary, aim towards the realistic narration of events while still maintaining a level of pretense as raw footage is subjected to editing which can affect the perception of the audience into a desired viewpoint (Bradbury and Guadagno 2020, 340). Usually the narrative of the documentary is structure in the editing stage after raw footage is collected. The resulting paradox that occurs in the context of self-reflexive or autobiographical documentaries is that while the documentary genre is expected to present its narrative objectively in order to preserve the authenticity of its realism, in certain cases this authenticity is withheld by the subjectivity of the director as the maker of the film is a part of its narrative. As previously mentioned in this paper, one instance of self-reflexivity is the breaking down of the fourth wall when the audience is no longer an outsider that is watching from an exterior but a participant that is being involved with what is happening on the screen and the characters within.

Rondot (2019, 92) states that "Documentaries affirm and encourage social, dialectic interaction between screen and viewer and between knowledge and interpretation." From the titles of No Home Movie (2015) and This Is Not a Film (2011) it is insinuated that both present a direct negation of what these works should not be considered as. A phrase with this particular structure of is famously known to be the textual component of René Magritte's The Treachery of Images which is alternatively known as This is not a Pipe. But according to what parameters or definitions do the directors of these works want the audience to disregard the characterization of film and home movie respectively?

Firstly, we need to identify the purpose autobiographical documentaries serve for the subject/ director and the audience. Rondot $(2019,91)$ provides a concise and direct reasoning for this which is that the documentarians want their story to be seen and heard. Similarly, the features of social media platforms are currently being used to raise awareness, inform, call attention to and share experiences with a multitude of users as the cyberspace offers the opportunity to have a voice where the circumstances of real world do not allow. This type of public expressivity has also become a norm in the age of social media where two-way communication channels are widely accessible.

Secondly, In the context of filmic narrative there are several components that help to build a story. Bordwell $(2007,6)$ enlists these as three dimensions which include the story world, the plot structure and the narration. If we were to apply these dimensions to This Is Not a Film (2011), which presents a reality that is currently happening in the lived world, neither the plot structure nor the narration adhere to narrative conventions as there is no resolve at the end of the film but rather the "film" itself becomes the resolve of the plot. Newberry (2017), defines self-reflexivity as "an artistic choice by the filmmakers in which they make their narrative aware of their nature in order to either question or critic the process of filmmaking." which accurately describes the purpose of this choice in the context of how Panahi titled and directed his work in order to avoid fitting the definition of what consist of a film and what composes a film. 
Examples of self-reflexivity as an expressive device in the work of directors who have produced autobiographical narratives can include speaking directly to the camera, mentioning the process of the "film" itself while being aware that the formal components of the production process do not correspond to what normally adheres to conventional film forms. Even when instances of self-reflexivity are included in movies, they are often planned and intended, rendering them inauthentic. Poulaki (2012, 1 ), explains the concept of self-reflexivity as an anti-narrative component that is slowly establishing its significance in the developing conventions of cinematic narrative. When looking at the case of Chantal Akerman's No Home Movie (2015), the audience is included in witnessing the intimate and personal moments that Chantal and her mother, Natalia, share while conversing about the past and their transgenerational trauma which are topics of considerable sensitivity. According to Ruby's $(1977,4)$ ideation of what reflexivity means in a documentary it is understood that

To be reflexive is to be not only self-aware, but to be sufficiently self-aware to know what aspects of self are necessary to reveal so that an audience is able to understand both the process employed and the resultant product and to know that the revelation itself is purposive, intentional and not merely narcissistic or accidentally revealing (Ruby 1977, 4);

while the convention of documentary filmmaking is to retain objectivity in order to present an accurate reality, this comes under question when the reality being present is autobiographical because the truth of that reality needs to reflect on the filmmaker within the film (Ruby 1997, 3). Self-reflexivity in cinema and other forms of audiovisual entertainment is still in the process of becoming accessible and normalized to audiences as traditional cinematic conventions have set expectations towards the establishment of perfection and planning in every shot (Poulaki 2012). For instance, when watching a Hollywood production, there is a certain expected standard that audiences hold in the development of the narrative, the quality of sound and image, the quality of special effects and the delivery of acting which in many cases if deemed to be lacking, results into the negative reception of the film (Künüçen 2014, 241). In documentary productions, the standard is still expected although to a lesser extent due to the non-fictional nature of the genre.

Finally, Ruby $(1977,3)$ characterizes the components that compose the final structure of a film as producer, process and product. Applying this formula of components to This Is Not a Film (2011), we find that the producer, the process and the product are all intertwined with each other and there is no way of separating one element without eliminating the others. Ruby $(1977,3)$, also mentions that conventionally the audience is only presented with the product while the process and the producer are considered to be part of what occurs behind the scenes rather than on screen.
Jafar Panahi considered the limitations imposed towards his right to make films and his condition under house arrest and no access to professional equipment or cast and thus conceptualized a project that would encompass the situation at hand. The self-reflexive stance of the resulting product justified the inclusion of all three components to be featured on screen as in this case of storytelling the very notion of what a "film" is, is questioned itself.

\section{Vlogging conventions in homebound documentaries}

Self-reflexivity is particularly normative in the domain of audiovisual content that is intended to be shared on online social media platforms. The video blog (or vlog) is known for its informal and casual presentation to the viewer and its intended function is only plausible if the creator of the vlog provides an invitation to establish a two-way channel of communication with the audience. Active engagement is required for the success of the vlog in the sense that appreciation is attributed to number of views, likes and comments.

Vlogging can be used as a form of diarization dedicated to self-expression and self-accounting in the context of everyday life (Ibrahim 2021, 330-331). The pace and rhythm of many movies avoids including moments where characters are engaged with actions that do not add anything to the purpose of the narrative. These moments could be denominated as fillers or padding depending on the context but in the specific "genre" of homebound documentaries these are the moments that enrich the "narrative" as they contribute to the subjective intake of information that the audience needs in order to fully grasp the emotional and formal value of this kind of cinematic experience. Looking at the formal elements that compose "A day in the life of..." category of vlogs, the embodiment of autobiographical narration that the viewer is faced with, is one its crucial advantages in the process of building a relationship between the creator and the viewer.

The interactivity that vlogging enables between the audience and the content creator establishes a sense of continued interest and dedication towards the content that is shared as even the most mundane aspects of life attract interest because of the relationship that viewers have with the vloggers. Thus, what further enhances the realistic feel of This Is Not a Film (2011) is the occurrence of slightly unexpected events throughout the day which the director does not know about either; some examples of these occurrences include Panahi's neighbor coming at his door to asking him to watch her dog or his conversation with the building caretaker whom he had never met before or his pet iguana climbing over his shoulder, which really capture some mundane moments of daily life. The fact that they have been included for the audience to see enhances the authenticity of Panahi's reality at home. The documentary was shot in the director's apartment on an iPhone and a digital camera due to the limitations 
that were imposed on the director's right to making films. In the final sequence of This Is Not a Film (2011), Panahi and Mirtahmasb are sitting at a dining table facing each other with their respective lenses while discussing their project and simultaneously recording each other. Similar to this, in one instance of No Home Movie (2015), Akerman takes a shot of her mother on a Skype call with her digital camera while facing her laptop's webcam while her mother asks her why she is filming her. The act of two cameras belonging to different types of digital devices facing each other challenges the conventions of indexicality in cinema as the audience gets to see the lens which is providing the point of view of what is being shown on the screen. Similarly, in No Home Movie (2015) there is a scene where Natalia asks Chantal why she is filming her while they are on a Skype call challenges the indexical purpose of the camera that which normally would have its presence concealed to the audience.

No Home Movie (2015) was primarily shot in home of Chantal Akerman's mother, Natalia, and presents the viewer with many instances of mundane life such as sitting in the living room, eating and conversing in the kitchen or just walking around the house. Shots of Natalia's home with no one in it are also included in the documentary as in certain moments, especially in real life, pauses, silence, emptiness and waiting are to be expected. The inclusion of such instances enforces the value that is placed upon the quotidian experiences of the 'authentic self' as cultural artefacts that preserve the intimacy of mundane moments (Ibrahim 2021, 331-332). The shots that Akerman takes of Natalia and her home have much in common with the atmosphere of homemade familial videos that are conserved and watched in later years to reminisce the memories of the past. Given that this film is not restricted to home viewing among the family members that are captured in it, is the first instance of audience involvement with Chantal and Natalia's story on an interpersonal level. Akerman places her camera around the house to self-record, allowing her to appear in the shot as well, this makes it seem like the audience is actually there in the room recording the moments of mother and daughter family time.

\section{How digital cinema is changing audience involvement with films and filmmaking}

The artificiality that has characterized the cinema of attractions for decades followed the logic that when people went to the cinema they desired to see the extraordinary as it inspired fascination, but in current times there has been a significant shift in what people deem as meaningful because the extraordinary is often accompanied by a sense of inauthenticity. The general public now has a basic understanding of how the special effects and the 'magic' of cinema come to life, therefore too much artificiality can result in disinterest and disengagement. Künüçen $(2014,239)$ considers how the changes occurring in the production process of films in the cinema industry has led to a critical reconsideration of what exactly defines film language in the digital age and explains how digital convergence has opened new avenues towards how films are viewed and distributed. The digitization of the film format now allows for films to be shared and watched online and consequently encourages a new appreciation for this form of cinema as well (Künüçen 2014, 239).

Interestingly, in recent years the concept of behind the scenes content has becomes a valuable asset as it helps audiences and fans to connect with the production process of films better. Footage involving interviews with cast and crew members, explanations of production processes, demonstration of the assemblage stages of the project invite spectators to become actively engaged. The boundaries of genre, convention and form are constantly being challenged. Amateur filmmaking is gaining a momentum of its own as the accessibility to cameras and platforms is becoming widely available (Künüçen 2014, 239). The strictness in the aesthetic and professional composure of cinema is facing a shift towards the appreciation of the mundane and the informal composure of audiovisual genres as these viewing experiences are easily relatable to an audience base that is significantly impacted by digital culture.

An aspect of inauthenticity that many movies are characterized by is the calculation and the planning that the product has undergone in its process stage as it is conventional for everything that the director decides to include in a shot to be functional and intentional for the development of the narrative. Sequences of shots are edited together based on cause and effect relations that dictate the reason for every action that takes place. In This Is Not a Film (2011) the opposite occurs as neither the audience nor the director really know what it going to occur next which gives a more realistic and natural feel to how the narrative unfolds. Even without the preplanned notion of cause and effect relations between events, the narrative still somehow results in a sequential order. In fact, the lack of conventional narrative structure is what enforces the value of Panahi's non-film because had he planned to shoot and include a specific order of events then the work might have felt inauthentic. Poulaki $(2012,8)$ explains that what separates non-fiction from fiction is the spontaneity of unplanned occurrences that trigger our sequence of daily life actions and choices. A realistic narrative can therefore never be fully planned or predetermined.

Unconventional works in the domain of cinema often challenge the definition of the traditional film form. Formality is constantly subjected to the technological and the cultural changes that occur in the digital age and the resulting category of works that can be categorized under digital cinema. The audience in the digital age of cinema is no longer a separate entity admiring from an outsider perspective rather the final product of digital cinema requires the audience to 
become an active participant whose input reflects on the purpose of the narrative. Cicognani $(2018,1)$ notes how certain elements of metacinematic expression that were once regarded as innovative, now have a much reduced effect due to the widespread use of self-reflexive tactics that the affordances of new media and digitization have enabled. The very idea of what is considered to be part of the codes that "dominant cinema" consists of, is no longer applicable to films that pertain to the digital cinematic expression (Polan 1978). In the past, the intended response of cinematic viewing experience was that of passive viewing in order for the audience to simply absorb and register what was being presented on the screen and thus the role of the spectator is rendered to be a non-acting subject (Polan 1978).

\section{Conclusion}

Throughout this paper the traditional conventions of cinema have been observed and discussed in the way that they have defined filmmaking since its early days. However, as narrative and storytelling are significant parts of human culture the impact of convergence is also reflected in how experiences are communicated among different art forms. Cinema began with the development of cameras that were able to shoot film and with the development of technology that has enabled us to have portable cameras on smartphones it is also possible to make films on such devices. The significance of the smartphone does not only stand in its affordances that allow access to filmmaking to the general public but also how our usage of them have become a consisted part of our lives in the digital age. As one of the most widespread communicative devices that enables the sharing of audiovisual content on social media platforms with other users, the smartphone is also impacting the formal conception of what makes a film as well as how a film should be viewed and received.

Filmmaking is no longer an art form constricted to the domain of the film studio and film watching is no longer constricted to the boundaries of the silver screen. Although the use of the fourth wall is an advantage to the narrative requirements of certain genres, it can result in alienating the audience as it provides a passive viewing experience which the audience cannot participate in. Alternatively, self-reflexivity in films (albeit still uncommon) is proving to be a device that provokes active thought and reaction regarding the issues that are being presented to the audience. This mode of storytelling highly resembles the way in which users engage with social media platforms as they can both assume the role of consumers and producers of content online. Furthermore, self-reflexivity is a normative components of content shared on social media platforms are these spaces provide the opportunity for self-expression and one of the primary purposes is to make use of the digital screen to communicate with others not only regarding trivial matters but also to incite reactions and awareness about the severity of individual and collective issues around the world. In the same way, the stories told in This Is Not a Film (2011) and No Home Movie (2015) intend to make us react and reflect on the challenges in the real world.

\section{Final Notes}

\begin{abstract}
${ }^{1}$ For the purpose of this paper, the definition of homebound documentaries will refer to documentaries that have taken place in a real-life home setting (not a set) and the majority of the events that unfold are limited to that setting.
\end{abstract}

\section{Bibliography}

Bordwell, David. 2007. Poetics of Cinema. New York: Routledge. https://doi-org.ezproxy.library.sydney.edu.au/ $10.4324 / 9780203941898$. Last access on 19/04/2021.

Bradbury, Judd D., and Guadagno, Rosanna E. 2020. "Documentary narrative visualization: Features and modes of documentary film in narrative visualization" in Information Visualization 19(4):339-352. https:// doi.org/10.1177/1473871620925071. Last access on 19/04/2021.

Ciccognani, Matteo. 2018. Metacinematic gestures: an investigation of the productionist aspect of self-reflexive films. Doctoral Thesis, University of Leicester.

Davis, Nathaniel. 2015. "“Not a Soul in Sight!": Beckett's Fourth Wall." in Journal of Modern Literature 38(2): 86-102. doi:10.2979/jmodelite.38.2.86. Last access 18/04/2021.

Friedberg, Anne. 2006. The Virtual Window: From Alberti to Microsoft. Cambridge: MIT Press.

Gunning, Tom. ed. Strauven Wanda. 2006. The Cinema of Attractions Reloaded. Amsterdam: Amsterdam University Press. https://www.jstor.org/stable/j.ctt46n09s. Last access on 19/04/2021.

Ibrahim, Yasmin. 2021. "Accounting the 'self': From diarization to life vlogs." in Convergence (London, England) 27(2):330-342. https://doi.org/10. 1177/1354856520947618. Last access on 19/04/2021.

Kings, M. J. W. 2017. "Review: JongoL Love: A SelfReflexive Movie Shot on a Mobile Phone." in Critical Interventions 11(1):73-76. https://doi.org/10.1080/1930194 4.2017.1309945. Last access on 18/04/2021.

Künüçen, Hidayet H. 2014. "The Effects of Digital Communication in Cinema: 'A New Film Language'." in Journal of Media Critiques 1(3):235-244.

Polan, Dana B. 1978. "Brecht and the Politics of SelfReflexive Cinema." in Jump Cut 17:29-.

Poulaki, Maria. 2012. "Self-reflexivity, Description, and the Boundaries of Narrative Cinema." in Cinéma\&Cie 18:45-55.

Rondot, Sarah Ray. 2019. "Against a Single Story: Diverse Trans* Narratives in Autobiographical Documentary Film." in Auto/biography studies 34(1):89-110. https://doi. org/10.1080/08989575.2019.1542826. Last access on $18 / 04 / 2021$

Ruby, Jay. 1977. "The Image Mirrored: Reflexivity and the Documentary Film." in Journal of the University Film Association 29(4):3-11. https://www.jstor.org/ stable/20687384. Last access on 18/04/2021. 


\section{Filmography}

Fight Club. (1999). Directed by David Fincher. USA: $20^{\text {th }}$ Century Fox. Amazon Prime.

Jongo Love (2015). Directed by Emma Bodger. Kenya: Well Told Story. YouTube.

No Home Movie. (2015). Directed by Chantal Akerman. France: Zeugma Films. MUBI.

This Is Not a Film. (2011). Directed by Jafar Panahi., France: Kanibal Films Distribution. Kanopy.

\section{Webgraphy}

Newberry, Alexandre. 2017. 10 Great Movies That Define Self-Reflexive Cinema. Tales of Cinema.http://www. tasteofcinema.com/2017/10-great-movies-that-define-selfreflexive-cinema/. Last access on 18/04/2021. 